\title{
Study of the Electrochemical Preparation of Atom-Scale Iron Quantum Wire Controlled by an External Resistor
}

\author{
Pei Zheng ${ }^{1,2}$, Juan Zhu ${ }^{1}$, Junhua Liu ${ }^{1}$, Xiaodong Dong ${ }^{1, *}$, Yong Xia ${ }^{3, *}$ \\ ${ }^{1}$ School of Medicine, Hebei University, Baoding 071002, China \\ ${ }^{2}$ Department of Neurology, Tianjin Medical University General Hospital, Tianjin 300070, China \\ ${ }^{3}$ State Key Laboratory of Electroanalytical Chemistry, Changchun Institute of Applied Chemistry, \\ Chinese Academy of Sciences, Changchun 130022, China \\ "E-mail: xddong8888@139.com
}

doi: $10.20964 / 2018.08 .33$

Received: 13 February 2018 / Accepted: 3 May 2018 / Published: 5 July 2018

In the present work, the stable atom-scale iron quantum wire was electrochemically prepared and characterized successfully by a homemade electrochemically controlled system. By adjusting the resistance of the external resistor, the atom-scale iron wire with preset conductance would be obtained. When scanned with low bias, the iron quantum wires showed the linear ohmic relationship for the current-voltage curve. With an external resistor control, the diameter, aspect ratio can be easily tailored, so it was a simple and controllable method. In addition, with a pure water environment of the preparation, the method had a less interference of other ions and was more suitable for sensor study of the quantum wire. The work was greatly significant for material science, molecular electronics, chemical and biological sensing.

Keywords: iron; atom-scale; magnetic materials; electrochemistry; quantum wire

\section{$\underline{\text { FULL TEXT }}$}

(C) 2018 The Authors. Published by ESG (www.electrochemsci.org). This article is an open access article distributed under the terms and conditions of the Creative Commons Attribution license (http://creativecommons.org/licenses/by/4.0/). 